\title{
Socioeconomic inequality in smoking and its determinants in the Islamic Republic of Iran
}

\author{
Mohammad Hassan Emamian, ${ }^{1}$ Mansooreh Fateh ${ }^{2}$ and Akbar Fotouhi ${ }^{3}$
}

${ }^{1}$ Ophthalmic Epidemiology Research Center; ${ }^{2}$ Center for Health Related Social and Behavioural Sciences Research, Shahroud University of Medical Sciences, Shahroud, Islamic Republic of Iran (Correspondence to: Mohammad Hassan Emamian: emamian@shmu.ac.ir). ${ }^{3}$ Department of Epidemiology and Biostatistics, School of Public Health, Tehran University of Medical Sciences, Tehran, Islamic Republic of Iran.

\begin{abstract}
Background: The role of socioeconomic inequality and related factors has not been well reported in tobacco consumption.

Aims: To investigate the socioeconomic inequality in smoking and its associated factors in the Islamic Republic of Iran.

Methods: Data were collected from surveillance for noncommunicable diseases in 2005, which included 89404 people aged 15-65 years. Economic status was defined by principal component analysis on variables related to socioeconomic status. Concentration index and slope index of inequality were used to determine the inequality value. The gap between the high and low economic status groups was decomposed using the Oaxaca-Blinder decomposition method for explained and unexplained components.

Results: The total prevalence of smoking was $17.0 \% ; 28.0 \%$ in males, and $5.8 \%$ in females, $15.8 \%$ in urban and $19.1 \%$ in rural areas. The concentration index was -0.032 in the whole of country; -0.098 , in males, -0.246 in females, 0.014 in urban and -0.059 in rural areas and varied in different provinces of country. The smoking rate was $18.0 \%$ for the first quintile and $13.5 \%$ for the fifth quintile, a gap of $4.5 \%$. The major part of this gap was related to differences in education level, sex, marital status and age in economic groups.
\end{abstract}

Conclusion: There was a pro-rich socioeconomic inequality in smoking, especially in females and in the southern provinces. Increase in education level and empowering females of low socioeconomic status are sound interventions for alleviating inequality and for tobacco control.

Keywords: smoking; health status disparities; inequality; Iran; socioeconomic factors

Citation: Emamian MH; Fateh M; Fotouhi A. Socioeconomic inequality in smoking and its determinants in the Islamic Republic of Iran. East Mediterr Health J. 2020;26(1):29-38. https://doi.org/10.26719/2020.26.1.29

Received: 01/04/19; accepted: 23/09/19

Copyright (C) World Health Organization (WHO) 2020. Open Access. Some rights reserved. This work is available under the CC BY-NC-SA 3.0 IGO license (https://creativecommons.org/licenses/by-nc-sa/3.0/igo).

\section{Introduction}

Tobacco consumption accounts for more than 7 million deaths annually. About $80 \%$ of smokers live in lowand middle-income countries (1). Previous studies have shown that the prevalence of smoking is higher among low-income and low-educated individuals (2-6). In 2008, the World Health Organization (WHO) categorized health disparities as a political agenda at local, regional, and national levels and made recommendations for this issue (7). In this report the accurate determination of the problem and the evaluation, monitoring and surveillance of inequality, both nationally and internationally, were emphasized (7); WHO even provided resources for examining national inequalities (8). However, in many lowand middle-income countries (and even in some high-income countries) there is no comprehensive national system for monitoring health inequalities (9). All societies today have socioeconomic inequalities and some degree of social gradient in health. This gradient should make us more aware of these inequities and of policy-making to address them; consider the determinants of inequality such as literacy (10); and even look politically at the inequalities (11).
Among people with low income or low literacy, smokers have a greater risk of death from chronic illness and tuberculosis (12). The relationship between tobacco control and equity is partly linked to the alleviation of poverty and the development of countries. In fact, many wealthy people in high-income societies have stopped smoking and do not socially accept this behaviour, while in low-income societies smoking is socially accepted and has a steady or growing status (12).

Previous studies in Thailand (13), India (14), Germany (in middle age) (15) and Indonesia (16) have shown that smoking is more frequent in low socioeconomic status or low-income groups. Even smoking cessation treatments were less used in groups with low socioeconomic status $(15,17,18)$. World Health Survey data from 48 low- and middle-income countries demonstrated that, in many countries, smoking is more common in low-income groups among males. Among females, it was both prorich (in 20 countries) and pro-poor (in 9 countries) (6). A limited number of studies also determined the causes of inequality in smoking (19-22), mostly using the decomposition of concentration index. As far as we know, there has been no study or comparison of this issue in the 
Islamic Republic of Iran across the different provinces. Our study reports on the factors relating to inequality in smoking employing a sample of adequate size in the Islamic Republic of Iran and its provinces.

\section{Methods}

The Ministry of Health and Medical Education established surveillance systems for noncommunicable diseases throughout the country in 2005. The first round of this surveillance was conducted in the same year with the participation of 89404 people. The participants were selected from all provinces using a systematic approach and a multi-stage cluster sampling method (23). The questionnaire used in this project was designed according to the WHO STEPwise approach. In this questionnaire 8 questions measured the socioeconomic status of participants, including type of home ownership, number of rooms, car ownership, number of trips in the past year, marital status, education level and primary job. Principal component analysis was performed on these questions, including 29 dummy, continuous and ordinal variables. The factors with an eigenvalue $>1$ (16 variables) covered $78.07 \%$ of variance. House ownership, occupation status, residence (urban/rural) and education level were the main significant variables with a high eigenvalue in the principal component analysis model. A new socioeconomic variable was constructed from the sum of the asset variables, weighted by the first eigenvector. The participants were then divided into 5 quintiles based on this new variable (24).

To estimate inequality, the prevalence of smoking was compared in socioeconomic quintiles and the concentration index and slope index for inequality (SII) were calculated. This method has already been used to examine socioeconomic inequality in hypertension (25) and obesity (26), and details of these methods are presented in those reports. People who currently smoke in any form (including cigarette, pipe, waterpipe) in any amount were considered smokers.

The gap between the 2 high and low socioeconomic status groups was divided into explained and unexplained components using the Oaxaca-Blinder decomposition method $(27,28)$. The explained component defines the difference in the independent variables between the 2 groups and the unexplained component is related to the difference in the effect of these variables between these 2 groups.

In all tests, the significance level was 0.05 , and the effect of cluster sampling was considered in calculating the confidence interval by using the "svy" command in Stata software (29). The distribution map of inequality was prepared using ArcGIS software (30).

\section{Results}

Of the 89404 people in the study, the smoking history was available for 87240 , and analyses were carried out on these participants: $50.2 \%$ were males, $64.9 \%$ lived in urban areas, mean age was 39.3 years and the age range was $15-65$ years. The mean age of smokers was 43.6 years and for non-smokers was 38.4 years. The difference was statistically significant $(P<0.001)$.

The prevalence of smoking was $17.0 \%$ overall, $28.0 \%$ in males and $5.8 \%$ in females. In urban areas prevalence was $15.8 \%$ and in rural areas $19.1 \%$. The prevalence of smoking varied in different provinces: those recording the lowest prevalence were Ilam (10.0\%), Yazd (10.6\%) and Golestan (11.2\%); those with the highest prevalence were the southern provinces of Bushehr (29.7\%), Sistan and Baluchestan (24.4\%), Kohgiluyeh and Boyer-Ahmad (21.9\%), and Hormozgan (21.5\%) (Table 1).

The status of socioeconomic inequality differed greatly between provinces. The concentration index was negative in Hormozgan (-0.209) and Bushehr (-0.201), indicating a significant inequality in favour of people with high socioeconomic status, and was close to zero in provinces such as Semnan (-0.001), Qom (0.005) and East Azarbaijan (0.006), indicating an absence of inequality, however, it was positive in Tehran (0.091) and Mazandaran (0.079), indicating a slight inequality in favour of individuals with low socioeconomic status (Figure 1).

These provincial differences caused the concentration index for the country as a whole to be non-significant (-0.032) (Table 1). The SII value also shows the same situation in absolute terms. In terms of this index, the least inequality was in East Azarbaijan province and the highest was in Bushehr province. The SII value was -0.72 for the whole country, which is not significant when considering the $95 \%$ confidence interval (-4.0-2.5).

The smoking situation in various socioeconomic groups was different in different provinces (Table 1). The prevalence of smoking in the first quintile was $6.6 \%$ in Tehran province and $32.8 \%$ in Hormozgan. The prevalence of smoking in the fifth quintile was $8.2 \%$ in Yazd province and $18.8 \%$ in Sistan and Baluchistan.

Figure 2 shows the status of the concentration index in terms of smoking prevalence and suggests that as the prevalence of smoking increases, the concentration index switches from positive and close to zero values to negative values. Figure 3 shows the concentration curves of smoking according to sex. Both curves are above the 45 degree line, meaning unequal distribution of smoking in favour of high socioeconomic groups. The inequality was greater in women.

The total value of the concentration index was negative-0.032 [95\% confidence interval (CI): -0.023, $-0.041]$, meaning that inequality was at the expense of people of low socioeconomic status and concentrated in this group of society. The concentration index was -0.098 (95\% CI: -0.089, -0.106), in men - 0.246 (95\% CI: -0.225 , -0.267 ) in women, 0.014 (95\% CI: 0.025, 0.003) in urban areas and -0.059 (95\% CI: $-0.045,-0.072)$ in rural areas. It can be said that the women smokers are generally concentrated in disadvantaged groups.

The prevalence of smoking was $18.0 \%$ in the first quintile of socioeconomic status and $13.5 \%$ in the fifth quintile, a gap of $4.5 \%$ (Table 2 ). The major portion of 





Figure 1 Concentration index of smoking in the provinces of the Islamic Republic of Iran, 2005

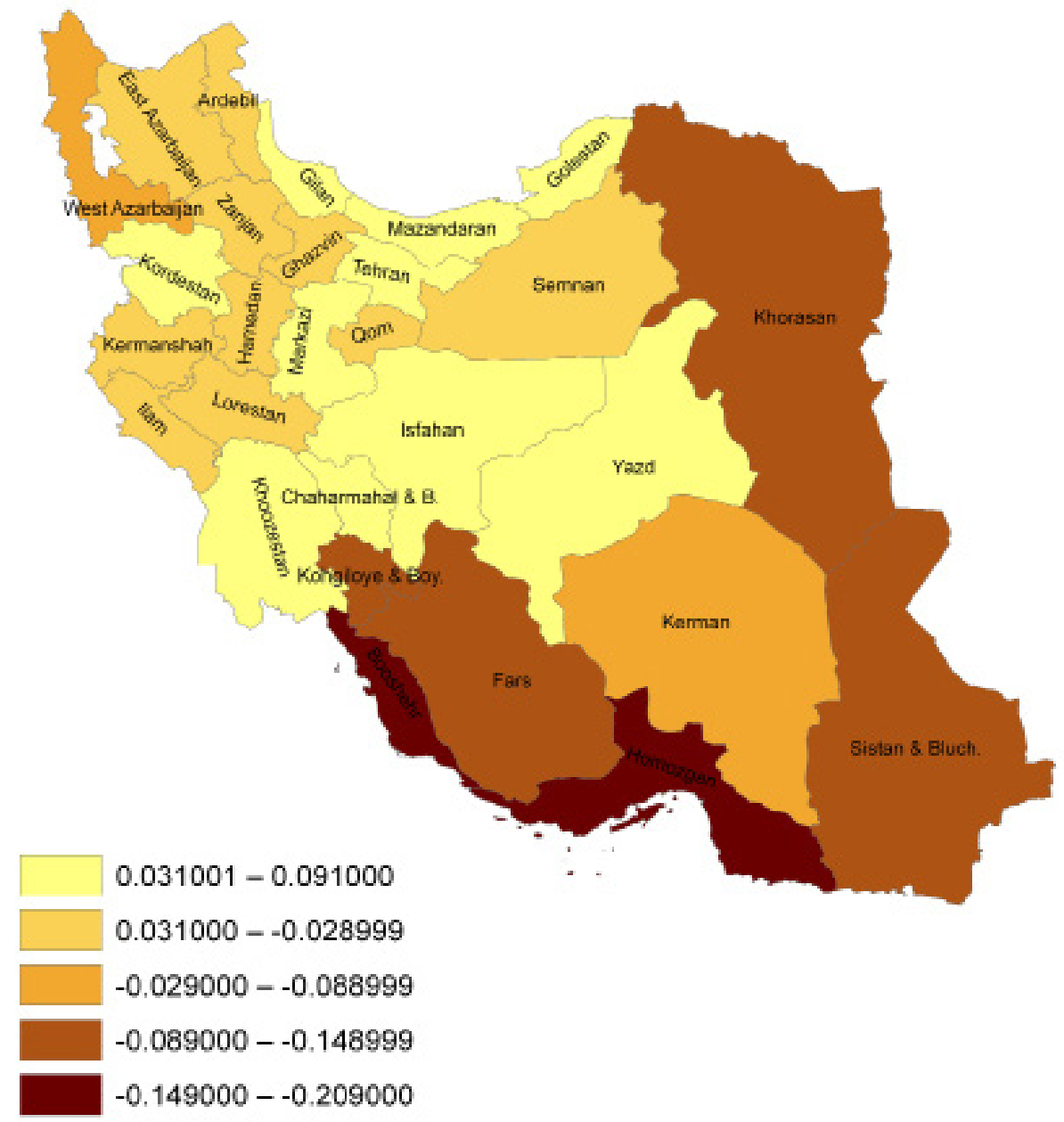

this gap was accounted for by the difference in the independent variables such as age and literacy (explained component): the mean years of education was 1.3 in the first socioeconomic quintile and 4.2 in the fifth quintile and the prevalence of smoking was higher in illiterate and less-educated individuals.

The share of the explained component is positive, which means that these differences are in favour of the high socioeconomic group, while the difference in the influence of these independent variables (unexplained component) was -2.7 and was in favour of the low socioeconomic group.

\section{Discussion}

The results of this study showed that there was a spectrum of socioeconomic inequality in smoking in the Islamic Republic of Iran. In some provinces, the concentration index was negative and inequality was in the favour of the high socioeconomic people; there was no significant inequality in some provinces; and the concentration index was positive and inequality was in favour of people of low socioeconomic status in some provinces.
The 2 theories of health selection and social causation play an important role in creating inequalities. In the theory of health selection, the changes in the health status lead to alterations in social status and healthier people have suitable social situations. The theory of social causation emphasizes that having a higher socioeconomic status has a better effect on health (29).

In a study of inequality in 48 low- and middle-income countries, the prevalence of smoking in men with lower incomes was higher in most countries, sometimes 2.5 times higher than in the rich ones (6). The pattern in women differed in that it was pro-rich in 20 countries, meaning that smoking was more frequent in females with lower incomes, and in 9 countries it was more frequent in wealthy women. Several local studies have examined the status of inequality in smoking. One of these evaluated 1064 high school students in Zanjan: the concentration index for regular smoking was -0.10 and the household economic status had the most important role in this inequality (30). A study in Kurdistan reported significant inequality in smoking in 2005 and 2009 (21). In Shahroud, the concentration index for smoking was 
Figure 2 The relationship between inequality and prevalence of smoking, Islamic Republic of Iran, 2005

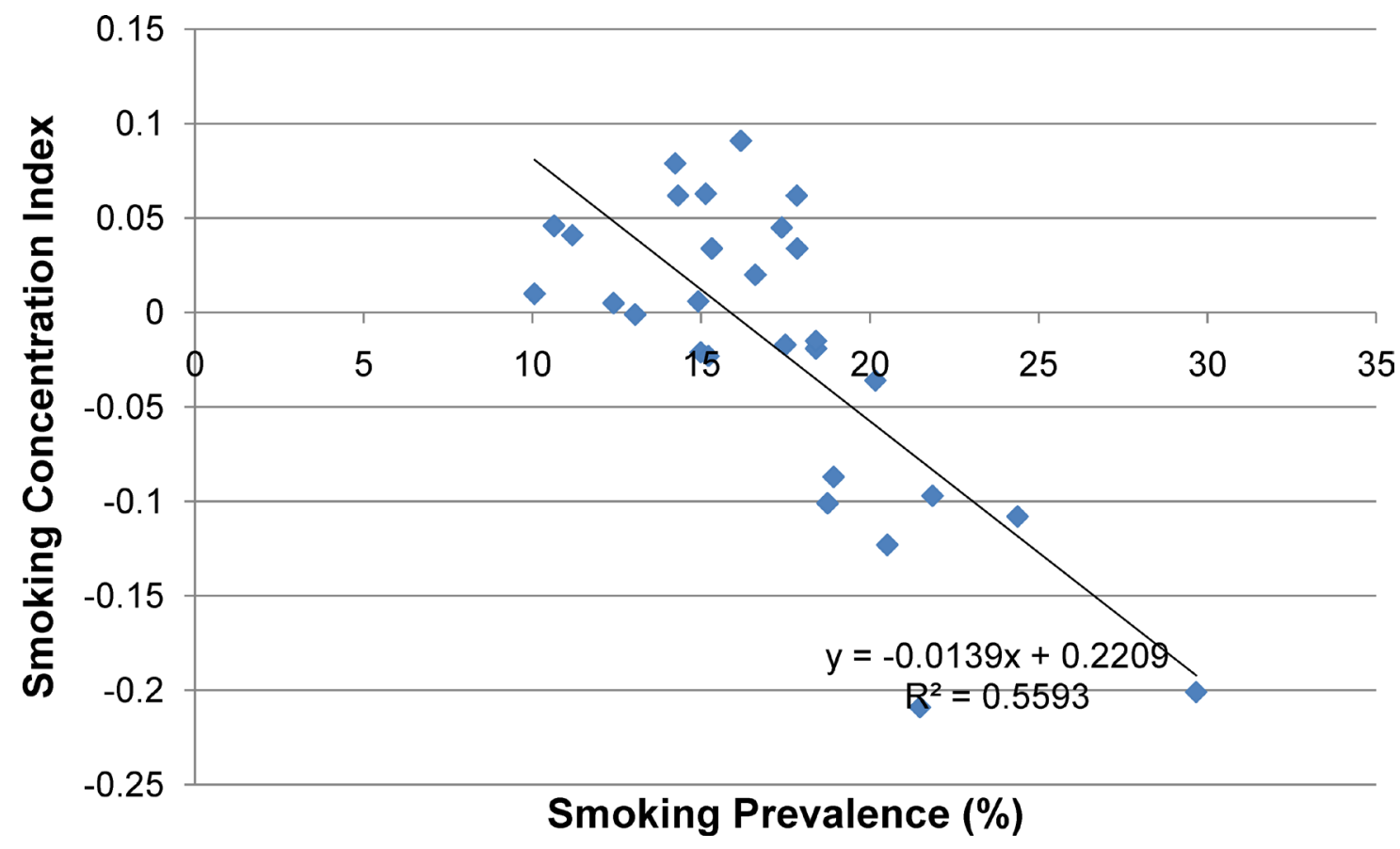

-0.191 (19). The differences in inequality in these studies can be attributed not only to the differences in inequality in the different provinces (also seen in the current study) but also to differences in the year of study, the target population and the selection of variables to measure the economic situation.
According to our findings, the increasing prevalence of smoking not only increases inequality but also moves away from focusing on advantaged individuals and concentrates on disadvantaged people. Additionally, we found that inequality was greater and the concentration index negative in the southern and eastern provinces.

Figure 3 The concentration curves for smoking among males and females in the Islamic Republic of Iran, 2005

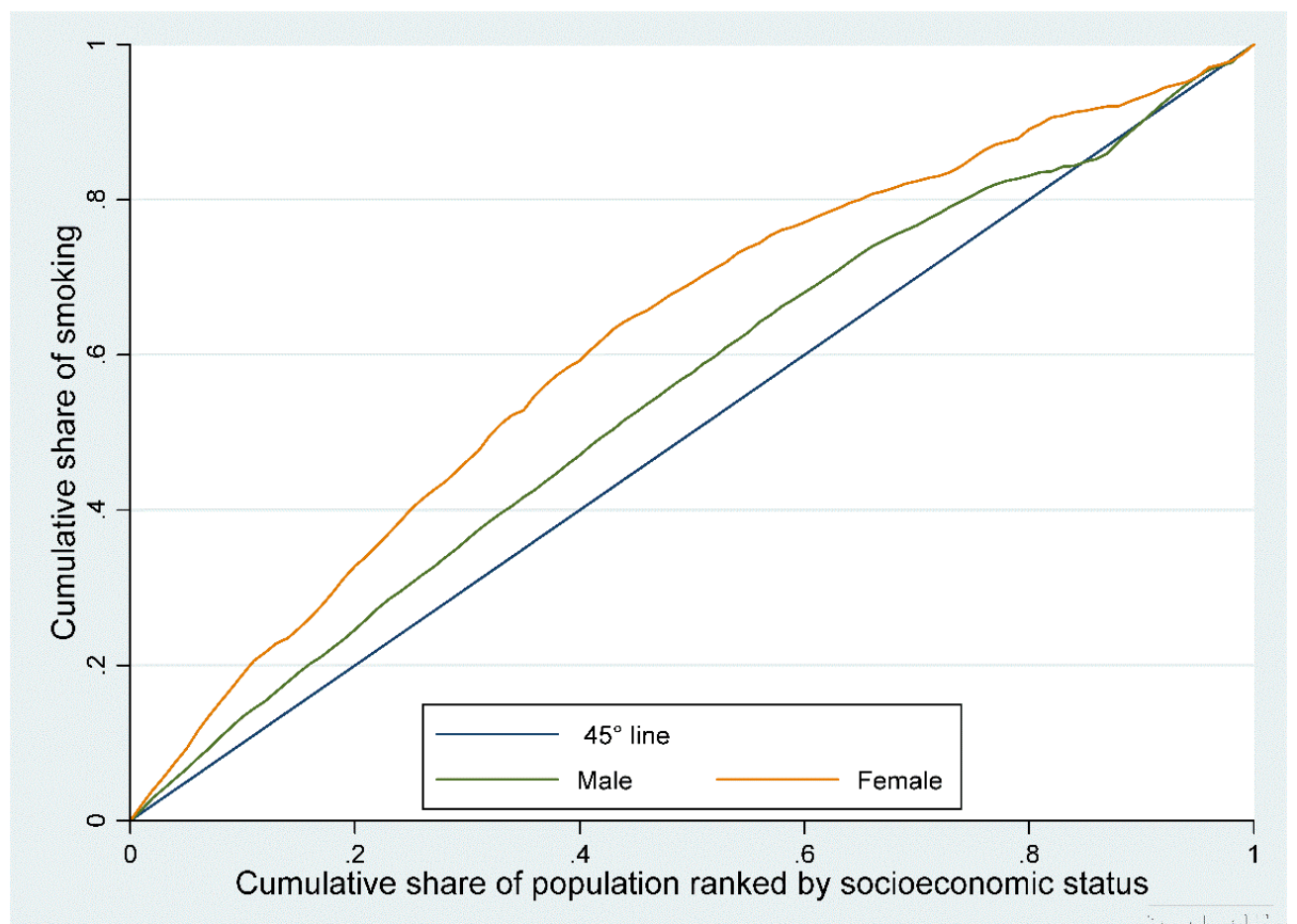


These provinces are more susceptible to smuggling, and this, coupled with the lower economic status of these provinces, probably leads to increased prevalence of smoking, especially among disadvantaged people. The relationship of people in the southern provinces with the Arab countries around the Persian Gulf (which have a higher prevalence of smoking) also contributes to the increased prevalence of smoking in these provinces.

Greater levels of deprivation in southern and eastern provinces have also contributed to the greater socioeconomic inequality in smoking. Similarly, research has shown that people in lower socioeconomic or lower income groups had a higher prevalence of smoking in the Czech Republic (31), in most districts of Korea (32), and among Indonesian teenagers (16). However, the prevalence of smoking was higher in Chinese males in the upper income rather than the low income group (33); in another Chinese study, the concentration index was 0.044 and tobacco consumption was concentrated in rich people (22). Therefore, it can be said that in other societies the inequality in smoking also differs depending on the prevalence of smoking and other factors, including per capita income. For example, a survey among adolescents aged 13-15 years in 63 low- and middle-income countries found that the prevalence of smoking increased with increasing GDP and the likelihood of smoking among youth was greater in countries with greater wealth inequality (34).

The results of decomposition of the gap between the low and high socioeconomic groups for smoking indicated that the main factors related to the differences in age, sex, education, residence and marital status between these socioeconomic groups. Among these variables, education had the greatest role and accounted for $64 \%(4.6 / 7.2)$ of the explained component. Further analysis showed that the mean years of education was much lower in the first socioeconomic quintile than in the fifth quintile and the prevalence of smoking was higher in illiterate and less-educated individuals. Indeed, if the education of disadvantaged people becomes equal to that of advantaged ones, a large proportion of the inequality will be eliminated. Other studies have pointed to the role of education in smoking.

For example, smoking was more common in lesseducated individuals in India (3,14) and China (33). In Switzerland, the less-educated individuals also had a higher prevalence of smoking and a lower quit ratio (35). World Health Survey data in 50 low- to uppermiddle income nations showed that increased education was strongly associated with a reduction in smoking, especially in young men, and the gap between educated and less-educated youth increased with growth in GDP. In women, the relationship between smoking and education was weaker (36). Data from 2004-2012 in 4 countries also revealed that smoking was more common in men in low educated groups in Lebanon, Palestine and the Syrian Arab Republic (37). Cross-sectional studies in Germany (38) and the United States (39) reported that, although there was a decreasing trend in smoking, this decline was only observed in groups with high and moderate education levels and did not change significantly in lower educated groups. In 4 European countries, United Kingdom, Finland, Lithuania and the Netherlands, it is anticipated that the prevalence of smoking will be reduced by 2050 , but this decline will occur mainly in the more advantaged groups, and inequality in education will increase the prevalence of smoking (40). In a survey in 49 countries, the prevalence of smoking was higher in higher-educated women aged over 45 in Eastern Europe and the Eastern Mediterranean (positive gradient), while this was the reverse in young females (4). The results of the above studies emphasize that in most societies, better education especially at younger ages, is associated with a lower smoking prevalence.

The next factor in creating inequality was sex, the impact of which was in favour of disadvantaged people, unlike other factors under investigation. The reason for this was that females with a lower prevalence of smoking (5.8\%) than males $(28.0 \%)$ were often found in the first socioeconomic quintile $(66.6 \%)$ rather than the fourth (28.9\%) and the fifth (43.1\%). Attention to empowerment, income and education of females in low socioeconomic groups is an important strategy for reducing inequality. World Health Survey data showed that globally the prevalence of smoking was $40 \%$ in males and $12 \%$ in females in all societies. The lowest prevalence (4\%) was found in Eastern Mediterranean females (36). In almost all countries, smoking is more common in poor males compared with rich males, while in females due to the increasing trend of smoking, different scenarios exist in different regions. The causes of the higher prevalence of smoking in poor people are complex and require further study.

Marital status was the next associated factor in the gap between the 2 groups for smoking. Further analysis showed that smoking prevalence was $19.8 \%$ in married and $8.4 \%$ in non-married (single, deceased spouse, divorced) people. On the other hand, $8.1 \%$ of the first quintile and $47.5 \%$ of the fifth quintile (who were younger people) were non-married participants. Contrary to these results, a study in China showed that the smoking prevalence and the number of cigarettes smoked were greater in singles, widowed and divorced participants (22). In addition to cultural differences, the main reason for this difference may be the age of people in various socioeconomic groups. In the present study, the age of the individuals was older in the lower quintiles, and therefore the percentage married was greater than in the other quintiles. It should be noted that what is seen in Table 2, as the association of different variables, is adjusted with the influence of other variables, including age. In other words, it can be said that marital status is also associated with smoking, independently of the age difference of people in different socioeconomic groups. In order to reduce inequality, further attention should be paid to non-married groups.

The age difference of various socioeconomic groups generated $31 \%$ of the gap between the 2 groups in the 


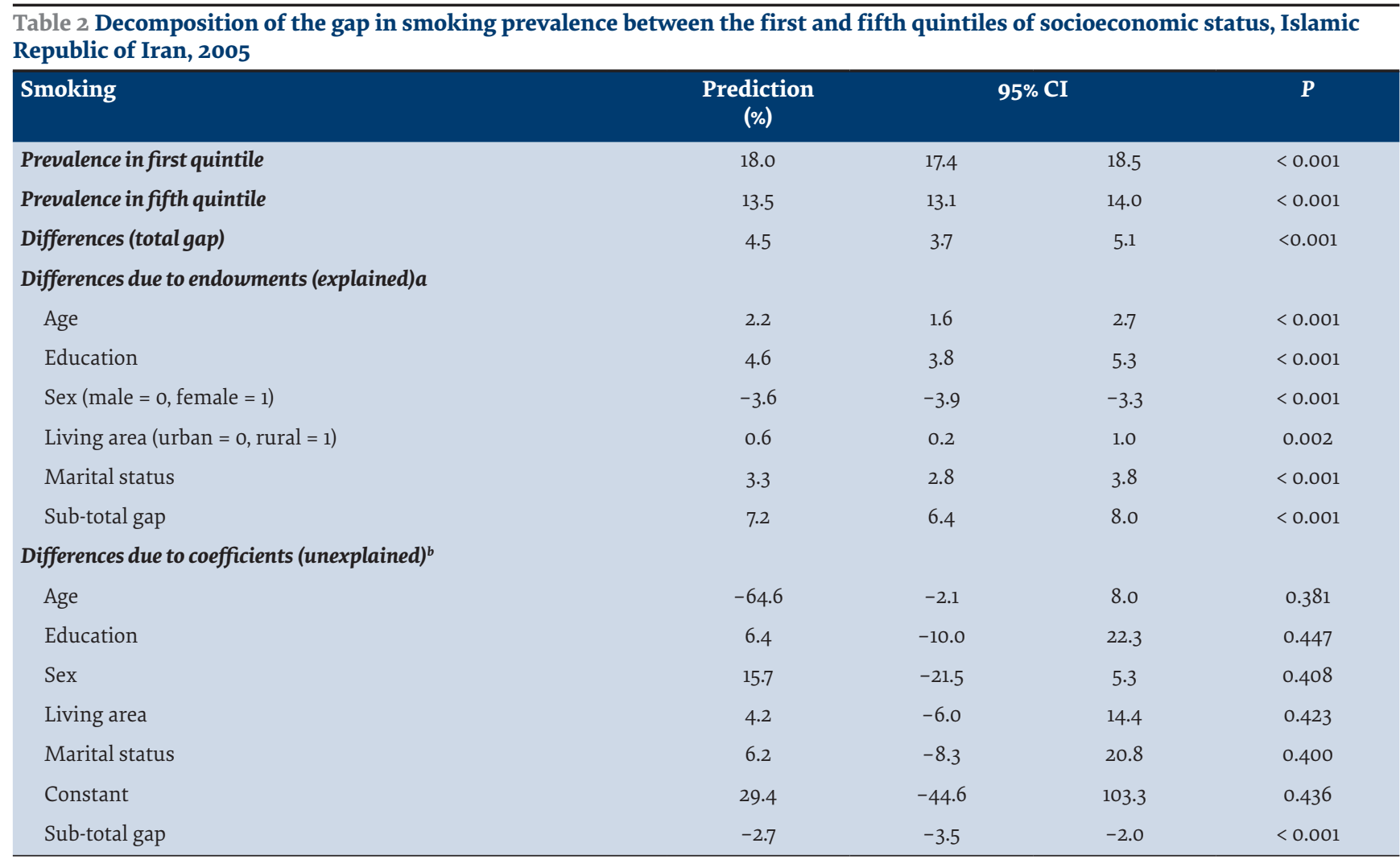

aPart of gap that related to differences in independent variables between two groups.

${ }^{b}$ Part of gap that related to differences of regression coefficients ( $\left.\beta s\right)$ in two groups.

$C I=$ confidence interval.

explained section. The cause of this association is that older people were in lower and younger people were in higher socioeconomic groups, and, as in other research (41), the mean age of the smokers was statistically significantly higher than that of the non-smokers. The message here is that to reduce inequality, new interventions for poverty alleviation and smoking cessation should focus especially on older people.

Residence had the smallest role in creating a gap between the 2 groups. The rural areas not only had a higher prevalence of smoking than urban areas but also had an absolute concentration index greater than urban areas (more inequality) and a negative concentration index, in contrast to urban areas. In the United States of America, despite the decline in smoking, it was more prevalent in less-educated people and in rural areas $(39,42,43)$. A higher prevalence of smoking in rural areas of China has also been reported (44).

The large sample size, the use of a national questionnaire and the gathering of information accurately and with monitoring and the use of accurate statistical methods for defining and decomposition of inequality were some of the strengths in this study. However, it should be mentioned that the study data were from 2005, and further longitudinal studies are necessary to understand the current situation. In interpreting the results, it should be noted that the observed relationships in this cross-sectional study had no causal aspect and only showed the relationships between variables.

\section{Conclusion}

There was a socioeconomic inequality in smoking in the Islamic Republic of Iran and most of its provinces. This inequality was in favour of advantaged people, very prominent in women and was greater in rural areas compared with urban areas. A higher prevalence of smoking enhanced the inequality and concentrated it in low socioeconomic groups. Education, sex, marital status and age were the main factors associated with this inequality, and these should be considered when developing tobacco control interventions.

\section{Acknowledgements}

The surveillance systems for noncommunicable diseases is part of the innovations of the Centre for Disease Control of the Iranian Ministry of Health and Medical Education. We thank the centre and all medical universities in the Islamic Republic of Iran that have attempted to design and implement this surveillance system.

Funding: This study was supported by Shahroud University of Medical Sciences (Project No. 9839).

Competing interests: None declared. 


\section{Inégalités socio-économiques liées au tabagisme et leurs déterminants en République islamique d'Iran}

\section{Résumé}

Contexte : Le rôle des inégalités socio-économiques et des facteurs connexes n'a pas été bien décrit dans la consommation de tabac.

Objectifs : Étudier les inégalités socio-économiques liées au tabagisme et les facteurs qui y sont associés en République islamique d'Iran.

Méthodes : En 2005, des données ont été collectées par le biais de la surveillance des maladies non transmissibles impliquant 89404 personnes âgées de 15 à 65 ans. Le statut économique a été défini par l'analyse en composantes principales des variables liées au statut socio-économique. L'indice de concentration et l'indice de pente de l'inégalité ont été utilisés pour déterminer la valeur de l'inégalité. L'écart entre les groupes de statut économique élevé et faible a été décomposé à l'aide de la méthode de décomposition Oaxaca-Blinder pour les composantes expliquées et inexpliquées.

Résultats : La prévalence totale du tabagisme était de $17,0 \% ; 28,0 \%$ chez les hommes et 5,8 \% chez les femmes, 15,8 \% en milieu urbain et $19,1 \%$ en milieu rural. L'indice de concentration était de - 0,032 dans l'ensemble du pays ; - 0,098 chez les hommes, - 0,246 chez les femmes, - 0,014 en milieu urbain et - 0,059 en milieu rural et variait selon les provinces du pays. Le taux de tabagisme était de 18,0\% pour le premier quintile et de 13,5\% pour le cinquième quintile, soit un écart de 4,5\%. La majeure partie de cet écart était liée aux différences de niveau de scolarité, de sexe, d'état civil et d'âge dans les groupes économiques.

Conclusions : Il y avait une inégalité socio-économique en faveur des riches dans le tabagisme, en particulier chez les femmes et dans les provinces du sud. L'augmentation du niveau d'éducation et l'autonomisation des femmes de faible statut socio-économique sont des interventions judicieuses pour réduire les inégalités et lutter contre le tabagisme.

$$
\begin{aligned}
& \text { عدم المساواة الاجتماعية والاقتصادية في التدخين ومحدداتها في جمورية إيران الإسلامية } \\
& \text { الخملاصدة حسن إماميان، منصورة فاتح،أ كبر فتوحي } \\
& \text { الخلفية: إن دور عدم المساو اة الاجتهاعية والاقتصادية في استهالكك التبغ والعوامل المرتبطة بذلك لم يتم الإبلاغ عنها جيداً. } \\
& \text { الأهداف: هدفت الدراسة إلى التحري بشأن عدم المساواة الاجتماعية والاقتصادية في التدخين و العوامل المرتبطة بذلك في جمهورية إيران الإسلامية. }
\end{aligned}
$$

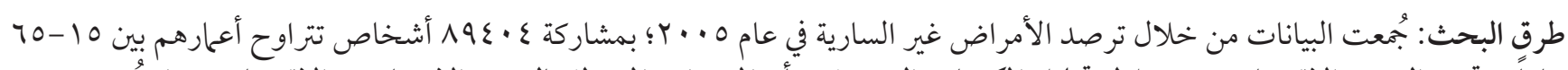

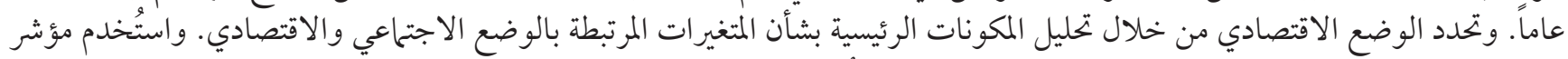

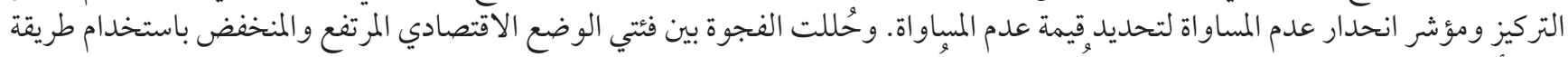

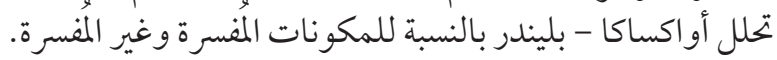

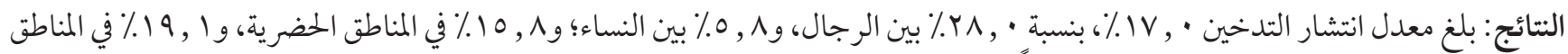

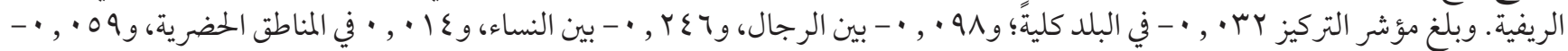

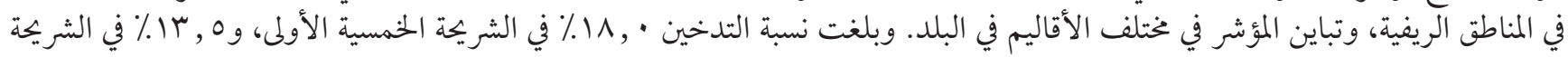

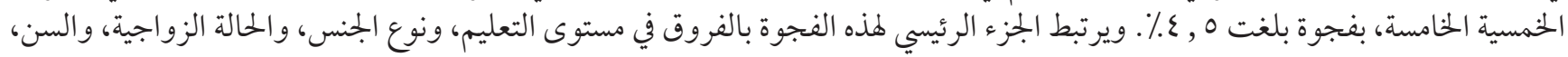

$$
\begin{aligned}
& \text { و الفئات الاقتصادية. }
\end{aligned}
$$

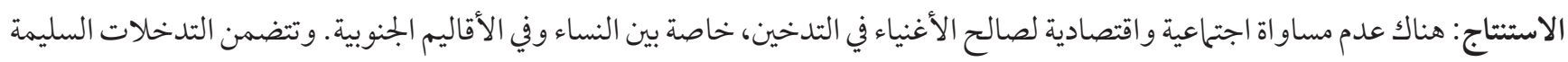

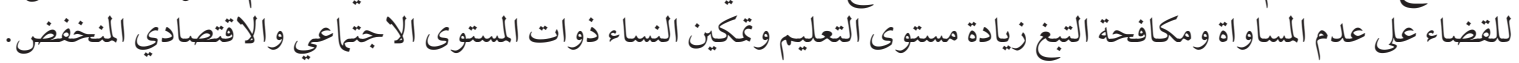

\section{References}

1. Tobacco: key facts. Geneva: World Health Organization; 2018 (http://www.who.int/en/news-room/fact-sheets/detail/tobacco, accessed 29 October 2019).

2. Allen L, Williams J, Townsend N, Mikkelsen B, Roberts N, Foster C, et al. Socioeconomic status and non-communicable disease behavioural risk factors in low-income and lower-middle-income countries: a systematic review. Lancet Glob Health. 2017 Mar;5(3):e277-89. doi:10.1016/S2214-109X(17)30058-X

3. Bobak M, Jha P, Nguyen S, Jarvis M. Poverty and smoking. In: Jha P, Chaloupka F, eds. Tobacco control in developing countries: Oxford University Press; 2000:41-61. 
4. $\quad$ Bosdriesz JR, Mehmedovic S, Witvliet MI, Kunst AE. Socioeconomic inequalities in smoking in low and mid income countries: positive gradients among women? Int J Equity Health. 2014 Feb 6;13:14. doi:10.1186/1475-9276-13-14

5. Center for Public Health Systems Science. Health equity in tobacco prevention and control. Atlanta: Centers for Disease Control and Prevention; 2014.

6. Hosseinpoor AR, Parker LA, Tursan d'Espaignet E, Chatterji S. Socioeconomic inequality in smoking in low-income and middle-income countries: results from the World Health Survey. PLoS ONE. 2012;7(8):e42843. https://doi.org/10.1371/journal. pone.0042843

7. Closing the gap in a generation. Health equity through action on the social determinants of health. Final report of the Commission on Social Determinants of Health. Geneva: World Health Organization; 2008 (http://www.who.int/social_determinants/ final_report/csdh_finalreport_2008.pdf, accessed 29 October 2019).

8. Hosseinpoor AR, Schlotheuber A, Nambiar D, Ross Z. Health Equity Assessment Toolkit Plus (HEAT Plus): software for exploring and comparing health inequalities using uploaded datasets. Glob Health Action. 2018;11(Suppl. 1):1440783. doi:10.1080/16549716.20 18.1440783

9. Hosseinpoor AR, Bergen N, Schlotheuber A, Boerma T. National health inequality monitoring: current challenges and opportunities. Glob Health Action. 2018 Jan-Dec;11(Suppl. 1):1392216. doi:10.1080/16549716.2017.1392216

10. Marmot M. The health gap: the challenge of an unequal world. Lancet. 2015;386(10011):2442-4. doi:10.1016/S0140-6736(15)00150-6

11. McCartney M. Margaret McCartney: Health inequality has to be political. BMJ. 2017 Jun 20;357:j2978. doi:10.1136/bmj.j2978

12. Slama K. Tobacco control and health equality. Glob Health Promot. 2010 Mar;17(1 Suppl.):3-6, 81-5, 91-5. doi:10.1177/1757975909358242

13. Intarut N, Pukdeesamai P. Socioeconomic inequality in concurrent tobacco and alcohol consumption. Asian Pac J Cancer Prev. 2017 Jul 27;18(7):1913-7. doi:10.22034/APJCP.2017.18.7.1913

14. Thakur JS, Prinja S, Bhatnagar N, Rana S, Sinha DN. Socioeconomic inequality in the prevalence of smoking and smokeless tobacco use in India. Asian Pac J Cancer Prev. 2013;14(11):6965-9. PMID:24377634

15. Lampert T, Thamm M. [Social inequality and smoking behavior in Germany]. Bundesgesundheitsblatt Gesundheitsforschung Gesundheitsschutz. 2004 Nov;47(11):1033-42. doi:10.1007/s00103-004-0934-0 (in German)

16. Kusumawardani N, Tarigan I, Suparmi, Schlotheuber A. Socio-economic, demographic and geographic correlates of cigarette smoking among Indonesian adolescents: results from the 2013 Indonesian Basic Health Research (RISKESDAS) survey. Glob Health Action. 2018;11(Suppl. 1):1467605. doi:10.1080/16549716.2018.1467605

17. Barnett R, Pearce J, Moon G. Community inequality and smoking cessation in New Zealand, 1981-2006. Soc Sci Med. 2009 Mar;68(5):876-84. doi:10.1016/j.socscimed.2008.12.012

18. Tottenborg SS, Clark AJ, Thomsen RW, Johnsen SP, Lange P. Socioeconomic inequality in the use of prescription medications for smoking cessation among patients with COPD: a nationwide study. Int J Chron Obstruct Pulmon Dis. 2018;13:1775-81. doi:10.2147/COPD.S158954

19. Emamian MH, Alami A, Fateh M. Socioeconomic inequality in non-communicable disease risk factors in Shahroud, Iran. Iranian J Epidemiol. 2011;7(3):44-51.

20. Ghelichkhani P, Yaseri M, Yousefifard M, Baikpour M, Asady H, Oraii A, et al. The gap of cigarette and hookah smoking between socioeconomic groups in Iran: effect of inequalities on socioeconomic position. Arch Iran Med. 2018 Sep 1;21(9):418-24.

21. Moradi G, Mohammad K, Majdzadeh R, Ardakani HM, Naieni KH. Socioeconomic inequality of non-communicable risk factors among people living in Kurdistan Province, Islamic Republic of Iran. Int J Prev Med. 2013;4(6):671-83.

22. Si Y, Zhou Z, Su M, Wang X, Li D, Wang D, et al. Socio-economic inequalities in tobacco consumption of the older adults in China: a decomposition method. Int J Environ Res Public Health. 2018;15(7).

23. Delavari A, Alikhani S, Alaodini F. A national profile of noncommunicable disease risk factors in the I.R. of Iran. Tehran: Iranian Ministry of Health and Medical Education; 2005; (http://www.behdasht.gov.ir/uploads/1_94_8.pdf, accessed 29 December 2011).

24. O’Donnell O, Van Doorslaer E, Wagstaff A, Lindelow M. Analyzing health equity using household survey data a guide to techniques and their implementation. Washington DC: World Bank; 2008.

25. Fateh M, Emamian MH, Asgari F, Alami A, Fotouhi A. Socioeconomic inequality in hypertension in Iran. J Hypertens. 2014 Sep;32(9):1782-8.

26. Emamian MH, Fateh M, Hosseinpoor AR, Alami A, Fotouhi A. Obesity and its socioeconomic determinants in Iran. Econ Hum Biol. 2017 Aug;26:144-50.

27. Blinder AS. Wage discrimination: reduced forms and structural estimates. J Hum Resour. 1973;8:436-55.

28. Oaxaca R. Male-female wage differentials in urban labor market. Int Econ Rev. 1973;14:693-709.

29. Kröger H, Pakpahan E, Hoffmann R. What causes health inequality? A systematic review on the relative importance of social causation and health selection. Eur J Public Health. 2015;25(6):951-60.

30. Ayubi E, Sani M, Safiri S, Khedmati Morasae E, Almasi-Hashiani A, Nazarzadeh M. Socioeconomic determinants of inequality in smoking stages: a distributive analysis on a sample of male high school students. Am J Mens Health. 2017;11(4):1162-8.

31. Csémy L, Sovinová H, Dvořáková Z. Socioeconomic and gender inequalities in smoking. Findings from the Czech national tobacco surveys 2012-2015. Cent Eur J Public Health. 2018;26(1):28-33. 
32. Kim I, Bahk J, Yoon TH, Yun SC, Khang YH. Income differences in smoking prevalences in 245 districts of South Korea: patterns by area deprivation and urbanity, 2008-2014. J Prev Med Public Health. 2017;50(2):100-26.

33. Wang Q, Shen JJ, Sotero M, Li CA, Hou Z. Income, occupation and education: are they related to smoking behaviors in China? PLoS ONE. 2018;13(2).

34. Li DX, Guindon GE. Income, income inequality and youth smoking in low- and middle-income countries. Addiction. 2013 Apr;108(4):799-808.

35. Sandoval JL, Leão T, Cullati S, Theler JM, Joost S, Humair JP, et al. Public smoking ban and socioeconomic inequalities in smoking prevalence and cessation: A cross-sectional population-based study in Geneva, Switzerland (1995-2014). Tob Control. 2018 Nov;27(6):663-669. doi: 10.1136/tobaccocontrol-2017-053986

36. Pampel FC, Denney JT, Krueger PM. Cross-national sources of health inequality: education and tobacco use in the World Health Survey. Demography. 2011;48(2):653-74.

37. Abdulrahim S, Jawad M. Socioeconomic differences in smoking in Jordan, Lebanon, Syria, and Palestine: A cross-sectional analysis of national surveys. PLoS ONE. 2018;13(1).

38. Hoebel J, Kuntz B, Kroll LE, Finger JD, Zeiher J, Lange C, et al. Trends in absolute and relative educational inequalities in adult smoking since the early 2000s: the case of Germany. Nicotine Tob Res. 2018;20(3):295-302.

39. Drope J, Liber AC, Cahn Z, Stoklosa M, Kennedy R, Douglas CE, et al. Who's still smoking? Disparities in adult cigarette smoking prevalence in the United States. CA Cancer J Clin. 2018;68(2):106-15.

40. Pérez-Ferrer C, Jaccard A, Knuchel-Takano A, Retat L, Brown M, Kriaucioniene V, et al. Inequalities in smoking and obesity in Europe predicted to 2050: findings from the EConDA project. Scand J Public Health. 2018;46(5):530-40.

41. Hamrah MS, Harun-Or-Rashid M, Hirosawa T, Sakamoto J, Hashemi H, Emamian MH, et al. Smoking and associated factors among the population aged 40-64 in Shahroud, Iran. Asian Pac J Cancer Prev. 2013;14(3):1919-23.

42. Curry LE, Vallone DM, Cartwright J, Healton CG. Tobacco: an equal-opportunity killer? Tob Control. 2011 Jul;20(4):251-2.

43. Liu L, Edland S, Myers MG, Hofstetter CR, Al-Delaimy WK. Smoking prevalence in urban and rural populations: findings from California between 2001 and 2012. Am J Drug Alcohol Abuse. 2016;42(2):152-61.

44. Wang N, Feng Y, Bao H, Cong S, Fan J, Wang B, et al. Survey of smoking prevalence in adults aged 40 years and older in China, 2014. Chinese J Epidemiology. 2018;39(5):551-6. 